\title{
The comparison of anxiety and depression levels in asthma and COPD patients
}

\begin{abstract}
Background: Both asthma and COPD affect mental health due to their impact on activities, sleep and social life of patients and can be resulted in anxiety and depression.

Objective: To determine and compare the prevalence of anxiety and depression in asthma and COPD patients.

Methods: Subjects without known psychiatric diseases were consecutively recruited from pulmonary and allergy out-patient clinics at the third level hospitals. Diagnosis of asthma and COPD was based on GINA and GOLD guideline, respectively. Depression and anxiety symptoms were evaluated using Beck Depression Inventory (BDI) and Beck Anxiety Inventory (BAI).

Results: Study group consisted of 53 patients- 30 with asthma and 23 with COPD. All patients had moderate-to severe diseases. COPD group was older, had more smoking history and higher number of hospitalization than those in asthmatics. Atopy rate and education level was higher in asthmatics than those in COPD group. The mean BDI and BAI scores were $17.96 \pm 12.39$ and $20.57 \pm 12.67$ in the whole group. Both group had similar degree of anxiety $(21.23 \pm 11.7$ vs. $19.7 \pm 14)$, whereas BDI score was significantly higher in COPD group than that in asthmatics $(15.63 \pm 13.6$ vs. $21 \pm 10.1)(\mathrm{p}=0.02)$. Age, gender, smoking history, education level, atopy status, number of emergency room admission was not correlated with scores of BDI and BAI for both group. The only effective parameter on BDI score in COPD patients was having comorbidities.
\end{abstract}

Conclusion: Both asthmatics and COPD patients regardless of their socio demographic and clinical features have similar degree of anxiety. In addition, COPD patients are more depressive than asthmatics. The study indicates that psychiatric evaluation should be a part of tailoring therapy in chronic respiratory diseases.

Keywords: COPD, asthma, anxiety, depression, mood disorders, BECK inventory
Volume 2 Issue 2 - 2015

\author{
Adile Berna Dursun,' Özcan A, ${ }^{2}$ Tuğba Çiç̧ek ${ }^{2}$ \\ 'Department of Internal Medicine, Recep Tayyip Erdogan \\ University, Turkey \\ ${ }^{2}$ Department of Pulmonology,Atatürk Chest Diseases and \\ Thoracic Surgery Training and Research Hospital,Turkey
}
Correspondence: Adile Berna Dursun, PortakallıkMah. Rize Prestij Konutları D:2I Merkez-Rize, Turkey, Tel +90 464 213049, Fax+90 4642170364 ,

Email aberna.dursun@gmail.com, berna.dursun@erdogan.edu.tr

Received: January 22, 2015 | Published: March 03, 2015

\section{Introduction}

Chronic obstructive pulmonary disease (COPD) and asthma are common chronic diseases and the cause of much morbidity and mortality worldwide. COPD has been estimated to occur in up to $25 \%$ of the population aged 40 years and older; besides asthma is affecting > 300million people worldwide. ${ }^{1,2}$ Psychiatric disorders also occur quite frequently in the general population. The most frequent psychiatric disorders are anxiety disorders (14\%) and mood disorders $(7.8 \%){ }^{3}$ Asthma and COPD significantly affect mental heatlh because they impact on activities, sleep and social life of both patients and their relatives. On the other hand, psychological chronic pulmonary diseases may lead to depression and anxiety due to high stress levels and general worries they cause in patients. ${ }^{4}$

Evidence have shown that individuals with asthma have twice risk of developing depressive symptoms as compared with those who do not have asthma. ${ }^{5}$ Although there is clear relationship between anxiety, depression and asthma, the association with asthma severity is controversial. ${ }^{6}$ Anxiety and depression are also well-recognized major comorbidities in COPD. ${ }^{7}$ Even mild COPD patients are 4 times more likely to have depressive symptoms as compared subjects without COPD. ${ }^{8}$
Depression in chronic diseases has a greater effect on general health than depression or asthma and COPD alone. Both asthma and COPD patients with depression have uncompliance to therapy, loss of disease control, more exacerbations, reduced health-related quality of life, increased health resource use and increased mortalility. ${ }^{9}$ Mood and anxiety disorders in patients with asthma or COPD are likely under diagnosed ${ }^{10}$ Furthermore, there are a few reports comparing anxiety and depression levels between asthma and COPD, particularly. Thus, the objective of the study was to determine and compare the prevalence of anxiety and depression in asthma and COPD patients with similar severity diseases.

\section{Methods}

\section{Study population and design}

A total of 53 adult patients ( $>18 \mathrm{yr})$ without known psychiatric diseases were consecutively recruited from the pulmonology and allergy outpatient clinics of 2 third level teaching hospitals in Turkey. Characteristics such as age, gender, level of education, smoking status, atopic status, duration and severity of diseases, number of emergency department (ED), number of hospitalization and comorbidities were recorded. After the clinical interview and physical examination, patients willing to participate completed self-assessment questionnaires. 
The psychometric instruments were administered by the nurse practitioners.

\section{Diagnosis of asthma}

Asthma was diagnosed by the presence of recurrent symptoms of wheezing, shortness of breath, cough, and demonstration of objective sign of reversible air- way obstruction (FEV1 $>12 \%$ of predicted) as stated by Global Initiative for Asthma guidelines. ${ }^{2}$ Severity of asthma was also determined according to the GINA.

\section{Diagnosis of COPD}

COPD was diagnosed by the presence of dyspnea, chronic cough and sputum production with post-bronchodilator $\mathrm{FEV} 1<80 \%$ of predicted normal; post-bronchodilator FEV1/forced vital capacity (FVC) $<70 \%$. $^{1}$ The patients were classified based on GOLD criteria.

\section{Assessment of depression and anxiety}

Beck anxiety inventory (BAI), a 21-questions multiple-choices self-report inventory, was used for measuring the severity of an individual's anxiety. Each question has four options, graded from 0 to 3 and a score of 3 indicating the greatest severity. BAI has a maximum score of 63 and 0-7 minimal anxiety, 8-15 mild anxiety, 16-25 moderate anxiety, and 26-63 severe anxiety. Beck depression inventory (BDI), a 21-item interview, measuring the characteristic attitudes and symptoms of depression. The questionnaireconsists of 21 multiple-choices questions, each with four options, graded from 0 to 3 , a score of 3 indicating the greatest severity of depression. BDI has a maximum score of 63 and 0-15 indicates healthy, 16-30 minimal level of depression, 31-46 mild depression, and 47-63 severe

Table I Demographic characteristics of the study population depression.

\section{Statistical analysis}

Statistical analysis was performed using the statistical package for social sciences (SPSS) version 16. Values were reported as mean \pm SEM. Base line demographics and clinical characteristics were compared among groups using student t-test, chi-square, and/or Fisher exact tests, as appropriate. $\mathrm{P}<0.05$ was regarded as statistically significant.

\section{Results}

The study group was consisted of 53 ( F/M: 18/35) patients with maen age of $49.92 \pm 17.07$ (19-83)years. There were 30 patients with asthma and 23 patients with COPD. COPD group was older, had more smoking history and higher number of hospitalization than those in asthmatics. Atopy rate and education level was higher in asthmatics than those in COPD group. All patients had moderate to severe diseases in both asthma and COPD groups. There was no significant Table 1 are summarized the demographic and clinical characterstics of the groups (Table 1).

The mean BDI and BAI scores were $17.96 \pm 12.39$ and $20.57 \pm 12.67$ in the whole group. Both group had similar degree of anxiety $(21.23 \pm 11.7$ vs. $19.7 \pm 14)$, where as BDI score was significantly higher in COPD group than that in asthmatics $(15.63 \pm 13.6$ vs. $21 \pm 10.1)$ $(\mathrm{p}=0.02)$ (Graphic 1). Age, gender, smoking history, education level, Atopy status, number of hospitalization and emergency room admission was not correlated with scores of BDI and BAI for both groups. The only effective parameter on BDI score in COPD patients was having comorbidities (Graphic 2).

\begin{tabular}{|c|c|c|c|}
\hline & Study population $\mathbf{N}=53$ & Asthma group $\mathbf{N}=\mathbf{3 0}$ & COPD group $N=23$ \\
\hline $\begin{array}{l}\text { Age, mean } \pm \text { SEM, years } \\
\text { (min-max) }\end{array}$ & $\begin{array}{l}49.92 \pm 17.07 \\
(19-83)\end{array}$ & $\begin{array}{l}38 \pm 10.87 \\
(19-63)\end{array}$ & $\begin{array}{l}65.48 \pm 9.3 \\
(49-83)\end{array}$ \\
\hline Gender, F/M, n & $18 / 35$ & $16 / 14$ & $2 / 21$ \\
\hline Diseaseduration, mean $\pm S E M$, years (min-max) & $\begin{array}{l}8.25 \pm 6.39 \\
(I-25)\end{array}$ & $\begin{array}{l}8.83 \pm 6.7 \\
(19-63)\end{array}$ & $\begin{array}{l}7.48 \pm 5.98 \\
(I-20)\end{array}$ \\
\hline \# ER admission ever & $9.11 \pm 17.01$ & $12.03 \pm 21.2$ & $5.3 \pm 8.1$ \\
\hline \# ER admission in thepreviousyear & $2.26 \pm 4.2$ & $2.3 \pm 5.4$ & $2.22 \pm 2.15$ \\
\hline$\neq$ hospitalizaiton ever & $2.19 \pm 6.93$ & $0.77 \pm 1.3$ & $4.04 \pm 10.2$ \\
\hline$\neq$ hospitalizaiton in thepreviousyear & $0.77 \pm 1.52$ & $0.2 \pm 0.5$ & $1.52 \pm 2.02$ \\
\hline \multicolumn{4}{|l|}{ Education level } \\
\hline Primary School Graduation & $13(24.5 \%)$ & $6(20 \%)$ & \\
\hline Secondary School Graduation & $20(37.7 \%)$ & $10(33.3 \%)$ & $\begin{array}{l}7(30.4 \%) \\
10(43.5 \%)\end{array}$ \\
\hline High School Graduation & 15 (28.3\%) & $9(30 \%)$ & $10(43.5 \%)$ \\
\hline College graduation & $5(9.4 \%)$ & $5(16.7 \%)$ & $6(26.1 \%)$ \\
\hline \multicolumn{4}{|l|}{ Smoking status } \\
\hline Non-smoker & $21(39.6 \%)$ & 20 (66.7\%) & I (4.3\%) \\
\hline Ex-smoker & $21(39.6)$ & $6(20 \%)$ & $15(65.2 \%)$ \\
\hline Smoker & II (20.8\%) & $4(13.3 \%)$ & $7(30.4 \%)$ \\
\hline
\end{tabular}


Table Continued..

Study population $\mathrm{N}=53 \quad$ Asthma group $\mathrm{N}=30 \quad$ COPD group $\mathrm{N}=\mathbf{2 3}$

Comorbidities
None
Endocrinologic disorders
CVS disorders
Atopic disorders
Bronchiectasis
Chronic renal failure

BAI, mean \pm SD

$\mathrm{BDI}$, mean $\pm \mathrm{SD}$
$14(26.4 \%)$

$5(9.4 \%)$

$15(28.3 \% 9$

$15(28.3 \%)$

$3(5.7 \%)$

I $(1.9 \%)$

$20.57 \pm 12.67$
$5(16.7 \%)$

$3(10 \%)$

$5(16.7 \%)$

$15(50 \%)$

$2(6.7 \%)$

$21.23 \pm 11.7$

$|5.63 \pm| 2.6 \mid$
$9(39.1 \%)$

$2(8.7)$

$10(43.5)$

I $(4.3 \% 9$

I (4.3\%)

$19.07 \pm 14.02$

$17.96 \pm 12.39$

$21 \pm 10.1$

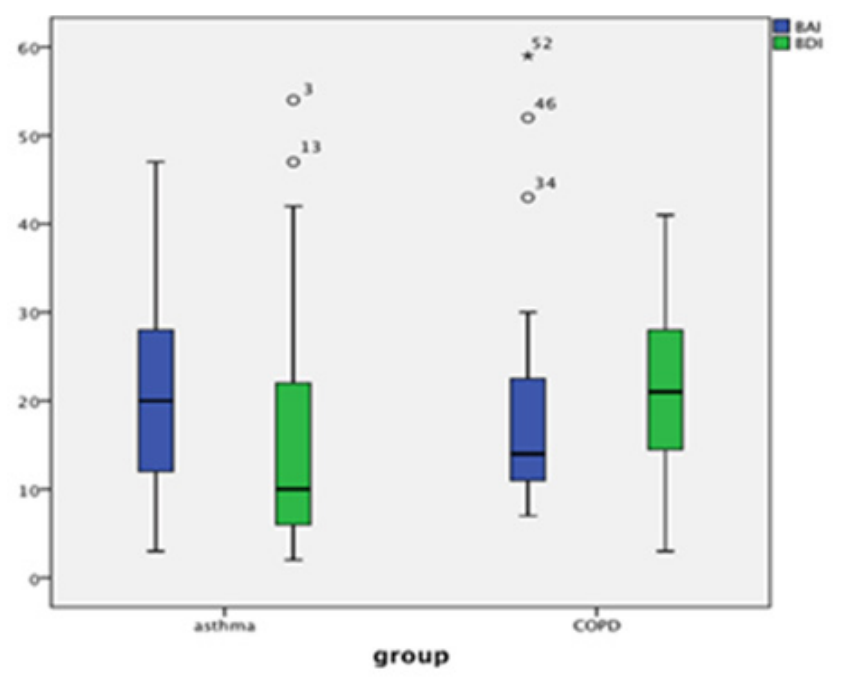

Graphic I Anxiety and depression levels of the groups.

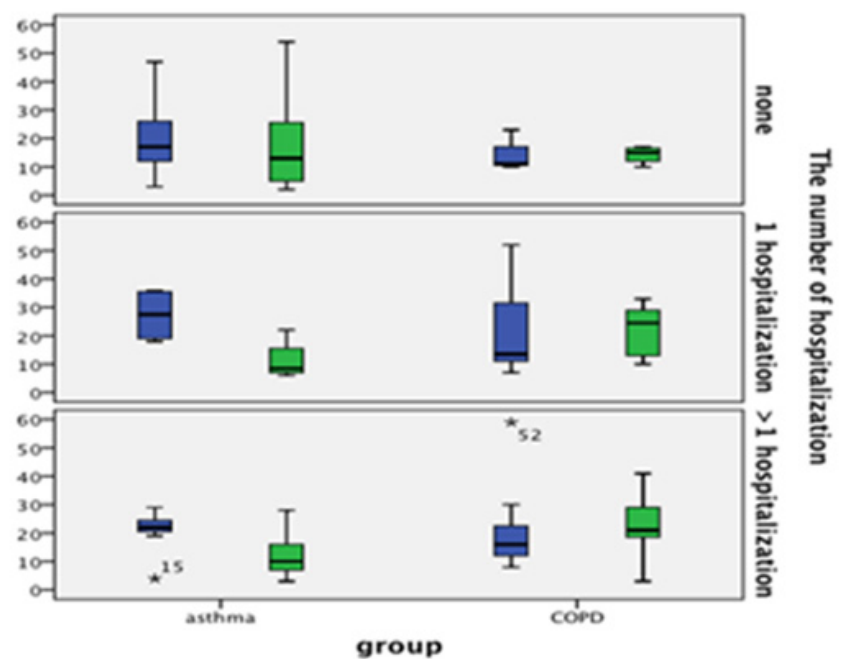

Graphic 2 Anxiety and depression levels of the groups according to the numbers of hospitalization.

\section{Discussion}

In the present study we demonstrated that both asthmatics and COPD patients regardless of their socio demographic and clinical features have similar degree of anxiety. In addition, COPD patients are more depressive than asthmatics. Psychiatric co morbidities are often observed in patients suffering from chronic somatic diseases. Particularly high prevalence rates of cognitive dysfunctions, depression and anxiety disorders have been reported for patients with asthma and $\mathrm{COPD}^{3}$ Like other major chronic diseases, both asthma and COPD has a significant impact on psychological well-being of people. Patients with COPD even in a mild stage have a higher prevalence of depression and anxiety than the general population. ${ }^{7}$ Although there are some controversies about the prevalence of depression and anxiety in asthma, it is estimated that depression and anxiety are 6 times more prevalent in asthmatics in comparison with general population. ${ }^{11}$

The data comparing the anxiety and depression in patients with asthma and COPD are in consistent. Carvalho et al reported that anxiety was more prevalent in asthmatics. ${ }^{12}$ On the other hand, more recently, Asnaashari et al demonstrated that there was not a significant difference between asthmatics and COPD patients in terms of general psychopathology, depression or anxiety. ${ }^{11}$ While , in this study we showed that although asthmatics and COPD patients have similar degree of anxiety, COPD patients are more depressive.

Risk factors for increased rates of depression and anxiety include gender, lack of social support, having more severe disease in COPD. Females have a higher rate of both anxiety and depression, and the rates of depression are more strongly correlated with severity of the disease compared with males. ${ }^{7}$ On the other hand, data about gender effect on psychopathology in asthmatics is inconsistent. While Wilson et al reported that both men and women had similar prevalence of psychological morbidities, Now obolski and Asnaaashari stated that asthmatic women experienced higher degrees of somatic symptoms and anxiety than men. ${ }^{11,13,14}$ However, in the present study, there was not statisticaly significant relation between the scores of anxiety/ depression and patient's socio demo graphics or clinical characteristics. The only statistically significant result was that COPD patients with having comorbidities had higher depressive scores.

Treatment of COPD and asthma is now aimed at immediately relieving and reducing the impact of symptoms, as well as reducing the risk of future adverse health events such as exacerbations. A frame work for chronic respiratory diseases management that matches individualized assessment of the disease to these treatment objectives will better meet each patient's needs. ${ }^{1,2}$ Untreated or incompletely treated depression and anxiety may have major implications for compliance with medical treatment, due to the effects on cognitive functioning and the decreased effectiveness of any self-management activities that the person may instigate. ${ }^{15}$ The study indicates that psychiatric evaluation should be a part of tailoring therapy in chronic respiratory diseases. 


\section{Acknowledgements}

None.

\section{Conflict of interest}

The author declares no conflict of interest

\section{References}

1. GOLD Global Initiative for chronic obstructive pulmonary disease. Global strategy for diagnosis, management, and prevention of COPD 2014.

2. GINA

3. Wittchen HU, Jacobi F, Rehm J, et al. The size and the burden of mental disorders and other disorders of the brain in Europe 2010. EurNeuropsychopharmacol. 2011;21(9):655-79.

4. Bratek A, Zawada K, Beil-Gawelcyzk J, et al. Depressiveness, symptoms of anxiety and cognitive dysfunctions in patients with asthma and chronic obstructive pulmonary disease (COPD):possible associations with inflammation markers: a pilot study. J Neural Transm. 2014

5. Jiang M, Quin P, Yang X. Comorbidity between depression and asthma via immune-inflammatory path ways: A meta-analysis. J Aff Disorders. 2014; 166:22-29.

6. Amelink M, Hashimoto S, Spinhoven P, et al. Anxiety, depression and person alitytraits in severe, prednisone-dependent asthma. Respir Med. 2014;108(3):438-444.

7. Pumar MI, Gray CR, Walsh JR, et al. Anxiety and depression-Important psychological comorbidities of COPD. J Thorac Dis. 2014;6(11):16151631.
8. Di Marco F, Verga M, Reggente M, et al. Anxiety and depression in COPD patients: the roles of gender and disease severity. Respir Med. 2006;100(10):1767-1774.

9. Miravitlles M, Molina J, Quintano JA, et al. Factors associated with depression and severe depression in patients with COPD. Respir Med. 2014;108(11):1615-1625.

10. Maurer J, Rebbapragada V, Borson S, et al. Anxiety and depression in COPD: current understanding, un answered questions, and research needs. Chest. 2008;134(4):43-56.

11. Asnaashari AMH, Talaei A, Haghighi MB. Evaluation of psychological status in patients with asthma and COPD. Iran J Allergy Asthma Immunol. 2012;11(1):65-71.

12. Carvalho NS, Ribeiro PR, Ribeiro M, et al. Comparing asthma and chronic obstructive pulmonary disease in terms of symptoms of anxiety and depression. J Bras Pneumol. 2007;33(1):1-6.

13. Wilson DH, Appleton SL, taylor AW, et al. Depression and obesity in adults with asthma: multiple comorbidities and management issues. Med J Aust. 2010;192(7):381-383.

14. Nowobolski R, Firgal M, Polczyk R, et al. Gender gap in psycogenic factors may affect perception of asthma symptoms. J Investig Allergol Clin Immunol. 2011;21(3):193-198.

15. Pooler A, Beech R. Examining the relationship between anxiety and depression and exacerbations of COPD which result in hospital admission: a systemic review. Int J Chron Obstruct Pulmon Dis. 2014;9:315-330. 